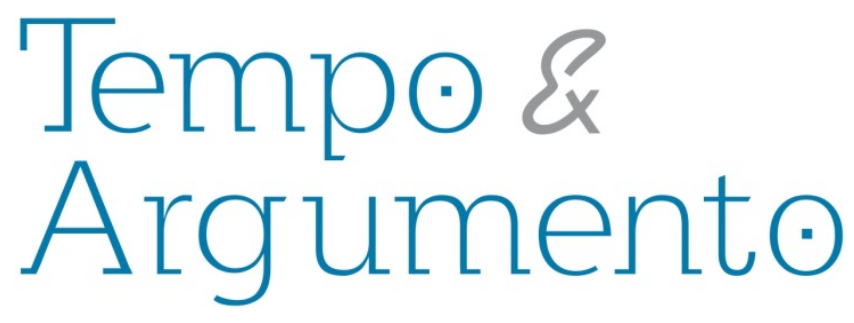

\title{
Crenças epistêmicas em mudança? Um estudo investigativo do conhecimento entre futuros professores de história
}

\section{Resumo}

Este estudo investiga crenças epistêmicas em mudança na área de história entre 18 futuros professores de história. Colhendo dados desses estudantes de graduação em história que estavam considerando seguir a carreira docente, o estudo procede a uma investigação sobre como as crenças epistêmicas podem mudar neste momento crucial de desenvolvimento. $O$ instrumento de escala Likert serviu como ferramenta para reunir dados primários e foi aplicado em um estágio antes e depois do curso. Dados de observação e de entrevista aumentaram os dados da escala. Um curso sediado em uma universidade serviu como veículo educacional com o objetivo de influenciar as crenças epistêmicas. Os resultados entre os futuros professores foram mistos. Algumas crenças epistêmicas dos alunos não se alteraram, enquanto outras mudaram, e algumas fortemente. As razões para as influências variadas são o tema da discussão. E as implicações dos resultados também serão considerados.

Palavras-chave: Conhecimento epistêmico; Pensamento histórico; Ensino de história; Futuros Professores.

\section{Bruce VanSledright}

Doutor e professor, coordenador do Doutorado em Educação Elementar. Universidade da Carolina do Norte. bvansled@uncc.edu

\section{Kimberly Reddy}

Doutora em Currículo e Educação. Possui longa experiência com pesquisa empírica e qualitativa e na escrita de diversas formas

de relatórios e artigos acadêmicos.

The Key School.

kimberly.m.reddy@gmail.com

Tradução

\section{Fabrício Coelho}

Mestre em Estudos da Tradução pela Universidade Federal de Santa Catarina fabricioconiglio@gmail.com

\section{Para citar este artigo:}

VANSLEDRIGHT, Bruce; REDDY, Kimberly. Crenças epistêmicas em mudança? Um estudo investigativo do conhecimento entre futuros professores de história. Revista Tempo e Argumento, Florianópolis, v. 6, n.11, p. 69-112, jan./abr. 2014. Título original: Changing Epistemic Beliefs? An Exploratory Study of Cognition Among Prospective History Teachers. Traduzido por Fabricio Coelho.

\section{DOI: $10.5965 / 2175180306112014069$}

http://dx.doi.org/10.5965/2175180306112014069 
Changing Epistemic Beliefs?

An Exploratory Study of

Cognition Among Prospective History Teacher

\begin{abstract}
This study explores changing epistemic beliefs in the history domain among 18 prospective history teachers. Drawing data from these college undergraduate history majors who were considering teaching careers, the study traces out an exploration of how epistemic beliefs may change at this crucial developmental point. A likert-scale instrument served as a primary datagathering tool and it was administered in a prepost, design. Observational and interview data augmented the scale data. A university-based course served as an educational vehicle designed to influence epistemic beliefs. The results among the prospective teachers were mixed. Some students' epistemic beliefs remained unaffected by the course, while others changed, some quite dramatically. Reasons for varied influences are the subject of the discussion. Implications of the results are also considered.
\end{abstract}

Keywords: Epistemic Knowledge; Historical Thinking; History Teaching; Prospective Teachers. 


\section{Introdução}

Danielle, uma professora experiente de história americana, ao responder a uma pergunta que lhe fora feita para discutir o que ela considerava ser a história e os papéis, fatos e interpretações que entram em jogo na tarefa de construir histórias, respondeu deste modo:

Para mim, a história nunca são apenas os fatos, porque você realmente não sabe o que ocorreu a menos que você pegue e pesquise, e então você sabe com certeza o que aconteceu naquele período de tempo. Então, você pode reunir informações sobre um evento histórico particular até certo ponto, mas dependendo dos documentos que você levantar ou das pessoas com as quais você falar, haverá sempre um viés, eu acho...

Ao tentar entender suas crenças sobre a história com base em comentários como esses, precisamos olhar de perto para o que ela diz. Em primeiro lugar, parece que ela acredita que o passado nos deixa fatos brutos para considerar. Contudo, a fim de dar a eles um sentido, alguma escavação adicional é necessária. Esta escavação implica o papel do investigador. Como tal, a história parece surgir da interação entre um interrogador (o conhecedor) e o passado e seus residua (o que está por conhecer, ou o objeto da tentativa de saber do conhecedor). Até aí tudo bem, ao que parece.

Então Danielle passa a falar mais sobre o funcionamento interno desta interação entre o conhecedor e os objetos históricos que estão por conhecer. Os conhecedores podem mergulhar nas profundezas do passado, mas apenas "até certo ponto". Aqui, o viés predomina. Com certa indiferença subentendida na sua frase final "eu acho", Danielle sinaliza que ela pode não pensar que o problema do viés seja superável. Como a sua voz diminui, ficamos nos perguntando se ela, como uma investigadora da história e uma conhecedora em potencial, possui algum critério para lidar com esse viés. Na parte inicial do seu comentário, ela parece convencida de que a pesquisa pode fornecer algum conhecimento histórico "seguro". Mas a sua frase que diminui parece desfazer a sua confiança. O viés parece ser tudo o que nos resta e temos pouca esperança, talvez, de lidar com isso de modo exitoso, enquanto tentamos chegar ao fundo do que "realmente aconteceu" no passado. 
Por que isso é importante? Em primeiro lugar, com manifestações no sentido contrário de algumas pessoas, o estudo histórico sério coloca os conhecedores numa posição paradoxal relativamente ao que eles querem saber sobre o passado. Como Joan Wallch Scott (1996) observou uma vez, não importa quanto um conhecedor queira dizer o passado como ele realmente aconteceu, dizer a verdade, por assim dizer, tal procedimento é negado porque ainda temos que encontrar os meios de reconstruir o passado e revivê-lo a fim de conhecer a sua verdade. O passado como ele realmente aconteceu está perdido para nós no presente. Tudo o que o conhecedor tem à sua disposição são cacos e restos e resíduos do passado que devem ser interpretados. $\mathrm{E}$ como Danielle parece lamentar, o viés vem à tona a cada vez. Todos os restos o contêm, e, o que talvez seja mais importante, também o tem o conhecedor, que não pode evitar interpretar a partir de suas âncoras temporais contemporâneas e das inescapáveis perspectivas que tem. No fim, tudo o que os investigadores da história parecem ter à sua disposição, se o seu conhecimento epistêmico está bem afinado, é o que o historiador James Kloppenberg (1989) chamou de um tipo de hermenêutica pragmática que não permite mais do que “... hipóteses, síntese provisória [e] interpretações imaginativas mas garantidas" (p. 1030). Danielle quer saber "com certeza", mas ela não pode. O que ela deve fazer?

E, em segundo lugar, esta é uma questão preocupante porque Danielle não é a única investigadora de história movendo-se entre os arquivos e tentando farejar a verdade do passado para a próxima história que vai escrever. Ela é uma professora de história americana do ensino médio, com mais de 100 alunos pelos quais é educacionalmente responsável todos os dias. Se ela ficar epistemologicamente e, por extensão, cognitivamente presa a este problema do viés, como ela ensinará aos seus alunos a lidar com isso? Ela tinha falado antes na entrevista sobre quão importante é ensinar às suas crianças o passado usando materiais que vão além dos relatos dos livros textos. Ela credita que isto é importante para o saber da sua profissão e para a sua tarefa de se tornarem melhores conhecedores. Mas no processo, ela corre o risco de sufocá-los no mesmo poderoso paradoxo do conhecedor/conhecimento, especialmente se os relatos e as fontes que ela lhes dá promovem conflitos interpretativos e estão emaranhados com o viés, algo que é quase, se não completamente, inevitável. Se ela não 
resolver esse problema para si própria, por meio de um tipo hermenêutica pragmática - e não há evidência a partir dos seus comentários de que ela resolveu - o que ela ensinará aos seus alunos quando eles se depararem com esta questão? Seus alunos se afastarão da leitura de relatos eivados de viés e conflito, com a ideia de que tudo é apenas viés, e portanto qualquer história que se poderia contar seria tão boa quanto qualquer outra porque se trata apenas da opinião de alguém? Claro, não podemos fazer nenhuma afirmação sem visitar a aula de Danielle. Seus comentários, contudo, são particularmente confortadores.

Tornou-se cada vez mais atraente para os professores de história oferecer leituras complementares com fontes outras que não os livros textos (e.g., HICKS et al, 2004). Relatos primários provocadores são particularmente preferidos pelos professores de história porque, dizem eles, aumentam o interesse e o engajamento. Ao passo que os livros textos são sempre chatos, relatos de primeira mão podem incitar melhor a curiosidade, provocar questões e despertar a atenção. Tais relatos também proliferaram na Internet, tornando a sua acessibilidade apenas uma questão de uns poucos cliques. Contudo, quais são as consequências para as crianças deste passo em direção da ampliação dos relatos? Como os professores as ajudam a lidar com o problema da perspectiva com a qual se deparam ao entrar neste mundo? E que ferramentas os professores têm nas suas caixas de ferramentas para lidar com este problema do conhecedor-conhecimento, ferramentas que eles poderiam disponibilizar nas suas salas de aula? Onde eles deveriam aprendê-las? Não se pode ensinar o que não se sabe. Estas questões serviram como base para o presente estudo.

\section{Literatura Relevante}

Passada mais de uma década desde o início do novo milênio, estudamos professores de história tais como Danielle no contexto de projetos de financiamento do ensino de história americana nos EUA. Tais projetos foram criados para remodelar como eles ensinam. Estes projetos se esforçaram para ajudar os professores a aprender como ensinar a prática do pensamento histórico aos seus alunos na pressuposição de que para entender o passado mais profundamente, os alunos precisam atualizar as suas práticas de 
pensamento. Em resumo, os diretores e formadores profissionais destes projetos tentaram aproveitar a pesquisa florescente no ensino da história num esforço para afastar as práticas dos professores das apresentações ubíquas de PowerPoint feitas de histórias recompiladas de livros textos, e aproximá-las mais do estudo da história como um empreendimento investigativo que depende de sermos capazes de pensar historicamente. Para ensinar o pensamento histórico, os diretores e formadores chegaram à conclusão razoável de que os professores precisam saber como fazer isto eles próprios. Nosso papel como avaliadores independentes nesses projetos nos ensinou que aprender a pensar historicamente é um feito difícil. Começamos a afinar a nossa atenção aos dados que estávamos colhendo dos professores que começavam a mostrarnos que um número de professores tinha crenças sobre a natureza do conhecimento histórico, donde ele vem e como é garantido, crenças estas que pareciam bloquear o seu progresso.

Efetivamente, muitos eram como Danielle. Eles podiam muito rapidamente chegar à ideia de que a história é um empreendimento interpretativo que se apoia na capacidade de pensar e raciocinar historicamente, de perceber que dar sentido à perspectiva é crucial. Contudo, eles ficariam então enjaulados no que alguns deles chamam de problema do viés. Ou seja, parecia-lhes que era um viés inescapável - em todo o percurso. Como se pode chegar a uma sólida interpretação se o viés e a opinião se insidiam em todo lugar? E, como menciona Danielle, relatos do passado - o lugar privilegiado do qual as interpretações poderiam ser extraídas - eram todos apenas opiniões e interpretações das pessoas radicadas nos seus posicionamentos pessoais do tempo. Muitos concluiriam que a história é o que quer que o investigador queria que fosse. Algumas histórias foram escritas simplesmente melhor e algumas foram retoricamente mais persuasivas, mas não necessariamente relatos que estavam mais perto do que realmente aconteceu. Estes professores se tornariam, às vezes a contragosto e com frequência desesperadamente, relativistas abjetos, presos numa posição epistêmica desconfortável segundo a qual não se poderia garantir o conhecimento na história a não ser quando dizemos que as histórias eram um pouco mais do que as opiniões de vários investigadores, e estamos todos legitimados a ter a nossa própria. Quando íamos visitar as suas aulas de vez em quando, 
Levantamos a hipótese de que os professores falharam em aprender explicitamente o que Kloppenberg (1989) chamou de hermenêutica pragmática, um processo, diz ele, que suplanta "o nobre sonho da objetividade científica" ao mesmo tempo em que se abstém do "pesadelo do relativismo completo" (p. 1030). A hermenêutica pragmática, se podemos dar crédito a Kloppenberg, parece ser o caminho que contorna o problema, pelo menos em história. Mas como alguém desenvolve uma posição epistêmica estruturada pela hermenêutica pragmática? Voltamo-nos à literatura de pesquisa para ver se e como outros pesquisaram esta questão, a saber, o problema do que fazer em que momento, nos termos de Kloppenberg, a busca da objetividade se torna impossível e a alternativa ao completo relativismo se parece mais com um niilismo assustador.

O conhecimento epistêmico pode ser entendido como "o processo cognitivo que habilita os indivíduos a considerar os critérios, os limites e a certeza do conhecimento" (MAGGIONI et al., 2009, p. 188). O posicionamento epistêmico de um indivíduo define o que ele considera conhecimento e como o conhecimento pode ser adquirido e aplicado. Estas concepções de conhecimento, que moldam as estruturas de crenças de um indivíduo (HOFER, 2002), impactam positivamente no seu entendimento do ensino e da aprendizagem de uma disciplina (HOFER, 2002; HOFER \& PINTRICH, 1997; LAMPERT, 1990; SCHOENFIELD, 1983); Dentro da área da história, estes hábitos de pensamento são usados para dar sentido a conceitos históricos, influenciar a habilidade de uma pessoa para trabalhar com textos históricos e afetar os vários modos em que ela aborda o estudo do passado.

Quando se consideram os modos pelos quais as pessoas pensam sobre a história, é importante reconhecer os seus entendimentos epistemológicos em torno da natureza do conhecimento deste campo. Especificamente, é importante considerar as relações entre o investigador - o conhecedor, e o passado - o que está por conhecer. Tais dimensões representam maneiras de conhecer, que ditam como e o que o aprendiz constrói como conhecimento. 
Frequentemente, indica a literatura, novatos abordam as fontes da história como "formas descontextualizadas, sem corpo e sem autor, de informações neutras que caem prontas do céu" (VANSLEDRIGHT, 2010, p. 116). Esta afirmação epistêmica é caracterizada por um entendimento da história como um espelho direto do passado. O conhecedor ou o investigador é ausente (MAGGIONI et al., 2009). Estes aprendizes não veem a diferença entre o passado e os relatos históricos, uma vez que acreditam que sejam uma coisa só. 0 conhecimento, como apresentado no interior de relatos históricos, é entendido como absoluto (KUHN \& WINSTOCK, 2002), ou dualista - estando ou certo ou errado (HOFER, 2001), e adquirido através de apresentações autorizadas (KING \& KITCHENER, 2002). Impasses cognitivos acontecem quando conflitos nas evidências vêm à tona, tais como quando documentos históricos apresentam ideias diferentes sobre o mesmo evento. Esses impasses deixam o investigador mentalmente paralisado e capaz de fazer pouco mais do que escolher ambiguamente um relato como a verdade com $\mathrm{V}$ maiúsculo (frequentemente um que seja oficializado pelas autoridades ou que soe particularmente como tal; ver PAXTON, 1999), ao passo que considera os outros como fictícios ou imprecisos em razão do viés ou do erro do autor.

Outros aprendizes têm o entendimento oposto sobre o conhecimento histórico. Esses aprendizes veem a criação do conhecimento histórico como o resultado de opinião. Eles "tendem a obter a sua história de relatos ou partes de relatos com base nas preferências instintivas ou na seleção casual” (MAGGIONI et al., 2009, p. 198). Também conhecidos como investigadores "recorta e cola", eles têm estratégias limitadas para julgar as fontes históricas (LEE \& ASHBY, 2000; VANSLEDRIGHT, 2011). Efetivamente, eles reconhecem o papel ativo do conhecedor no processo de geração do conhecimento. Mas um entendimento ingênuo da perspectiva e do posicionamento do autor os conduz frequentemente a concluir que todos os relatos históricos são igualmente enviesados e/ou igualmente dignos ou indignos de confiança, conforme o caso (LEE \& SHEMILT, 2003; MAGGIONI et al., 2009). Portanto, esses conhecedores de outrora equalizam o conhecido (ou seja, o passado) com qualquer relato que eles possam compor. Contudo, frequentemente eles descobrem com rapidez que recortar e colar falha em resolver o problema de conhecer e entender. Mais impasses cognitivos se seguem. Não tendo o 
entendimento epistêmico para cobrir essas lacunas (isto é, critérios de julgamento associados com o conceito de confiabilidade), esses conhecedores frequentemente acabam frustrados e incapazes de ir adiante com a construção de entendimentos históricos (LEE, 2004). Lembramo-nos aqui de Danielle.

Finalmente, há ainda uma terceira posição epistêmica frequentemente usada para caracterizar as afirmações epistemológicas de aprendizes que desenvolveram modos de conhecer com mais perícia. Esses conhecedores acreditam que a construção da história não é nem absoluta nem relativa. Em vez disso, eles entendem a importância da heurística disciplinar no desenvolvimento de interpretações históricas autênticas. Eles veem o conhecimento como ativamente construído (KING \& KITCHENER, 2002) pelo conhecedor através do uso da lógica conjetural. Está sempre evoluindo e os modos de conhecer estão sempre em harmonia com o julgamento das evidências e com a justificação (HOFER, 2001). Falando de modo geral, eles são capazes de reconciliar os impasses frequentemente experimentados por outros tipos de conhecedores reconhecendo o posicionamento da evidência, usando entendimentos procedimentais, que exigem que a evidência seja cuidadosamente avaliada no que diz respeito à consistência e à confiabilidade, e cobrindo as lacunas entre relatos usando o sequenciamento lógico dos eventos e contextos. Esta afirmação liga diretamente e coordena o papel do conhecedor, ou do investigador histórico, com o que está por conhecer (o passado) por meio da aplicação de critérios e ferramentas para tomar decisões. Esses conhecedores parecem utilizar uma hermenêutica pragmática (KLOPPENBERG, 1989).

Tanto as experiências prévias quanto as crenças epistêmicas dos aprendizes são essenciais para o entendimento de como eles negociam as conceitualizações necessárias para participar do pensamento histórico de modo que aprimorem os seus entendimentos. Para auxiliar no estudo continuado de como a conhecimento histórico evolui, os pesquisadores construíram modelos de progressão voltados a entender melhor o desenvolvimento de afirmações epistêmicas no campo da história (e.g., LEE \& ASHBY, 2000; LEE \& SHEMILT, 2003). Em razão da apresentação hierárquica dos modelos de progressão, eles trazem às vezes a implicação de que os alunos trabalham de menos para 
mais poderosas ideias (LEE \& SHEMILT, 2003). Contudo, os pesquisadores advertem que esses modelos não devem ser entendidos como lineares.

O pensamento histórico como um processo e um método para conhecer é um campo cognitivo que acaba sendo frequentemente muito fluido com respeito a como os indivíduos se movem epistemologicamente de um nível ao outro. Lee e Ashby (2000) sugerem, contudo, que há um modelo que pode ajudar a avaliar os parâmetros pelos quais os aprendizes se movem para mais perto ou para mais longe de entendimentos mais aprofundados do passado. Os modelos de Lee e Ashby e de Lee e Shemilt (2003) ilustram o avanço típico dos indivíduos à medida que aprendem a raciocinar historicamente. Este modelo de progressão pode ser ilustrado pela Figura 1.

\section{Figura 1. Um modelo de movimento epistêmico em relação com o entendimento do passado}

1. O passado é dado

2. O passado é inacessível

3. O passado como histórias que qualquer um poderia contar

4. O passado como reportado de um modo enviesado

5. O passado selecionado e organizado a partir de um ponto de vista

DE MENOS

PARA MAIS

PODER

COGNITIVO/

EPISTÊMICO

6. O passado como reconstruído

Pesquisas sobre crenças epistêmicas lançaram apenas uma luz parcial nas crenças epistêmicas do aprendiz de história porque os estudos frequentemente usaram questionários genéricos (e.g., STR $\varnothing \mathrm{MS} \varnothing$ \& BRÅTEN , 2006), faltando assim componentes especificamente pertencentes ao campo, como sugerido na literatura (BUEHL \& ALEXANDER, 2001; MUIS \& HAERLE, 2006). E, inversamente, os pesquisadores que focalizaram especificamente o campo da história (e.g., Lee \& Asby, 2000) inferiram principalmente as crenças epistêmicas dos alunos a partir da sua performance em tarefas específicas (e.g., ler múltiplas fontes históricas ou escrever narrativas baseadas em documentos). Como resultado, as descrições das ideias epistêmicas dos alunos à medida que emergem nas suas vozes são relativamente escassas. 
Esse estudo investiga as crenças epistêmicas no campo da histórica de modo mais direito e focalizado, com o propósito de contribuir com uma descrição mais aprofundada das ideias mantidas pelos aprendizes e de identificar os fatores facilitadores e as potenciais causas de tropeço (i.e., impasses cognitivos) no desenvolvimento epistêmico do campo. Trabalhando com alunos veteranos de graduação de história no EUA, este estudo investiga como as crenças em história podem mudar neste ponto crucial de desenvolvimento. A fim de iniciar o estudo, desenvolvemos uma moldura teórica que se alimentou da literatura acima mencionada, de nossos esforços prévios de pesquisa e de um conjunto de pressuposições teóricas.

\section{Moldura teórica}

Antes das suas carreiras em escolas nos EUA, muitos professores como Danielle passaram por extensas experiências nas salas de aula com a história tradicional, feita para o consumo na escola. Durante esses anos de formação, os futuros professores desenvolvem os seus próprios entendimentos do que significa ensinar e aprender (BRITZMAN, 1991). Os aprendizados por observação (LORTIE, 1975) podem ser centrais para a construção de crenças epistêmicas sobre o conhecimento histórico. Eles frequentemente moldam valores duradouros “...sobre a natureza das matérias escolares, como os professores e os alunos devem se comportar em sala de aula e o que constitui o ‘bom' ensino” (KENNEDY, 2005, p. 14). Os aprendizados podem continuar até e à vezes através dos programas de preparação docente. Com isto queremos dizer, por exemplo, os tipos de aula de história dados para cursos de história em salas de aula universitárias do tempo das cavernas por um professor que fala a partir de uma apresentação em PowerPoint. Nossa pressuposição é que, com apoio da literatura, estes tipos de didática de ensino e aprendizagem são comuns e ajudam a formar e a solidificar o fundamento sobre o qual os futuros professores de história chegam a entender o que é a história (CUBAN, 1991). Eles também reforçam e são reforçados pela cultura de consumidor, especialmente nas nações ocidentais. 
Se os futuros professores de história não tiverem o seus aprendizados de história escolar interrompidos nos seus cursos de graduação de história, então a estrutura típica dos programas de preparação de professores mais tradicionais dispensa pouco tempo para fomentar a mudança epistêmica significativa necessária para engajar os professores em práticas, ideias, crenças e critérios de julgamento que as pesquisas mostram melhorar o entendimento. Assim, pensamos, a lacuna que existe pelo menos nos EUA entre como futuros professores são expostos à história antes da preparação formal de professores, por um lado, e, por outro, um entendimento da natureza de como a história trabalha epistemologicamente desde o conhecedor até o que significa conhecer. Por conseguinte, perguntamos: Onde se espera que os futuros professores de história adquiram esse conhecimento e esse entendimento epistêmico e em qual contexto de aprendizado eles deveriam ocorrer?

Experiências com professores como Danielle, juntamente com a literatura sobre crenças epistêmicas na história serviram como base teórica para o nosso propósito de um curso que futuros professores de história poderiam fazer antes da sua entrada em um programa formal de preparação de professores. O curso foi desenvolvido com três objetivos em mente, radicados nas seguintes teorizações: (a) ajudar os matriculados a examinar os tipos de crenças epistêmicas que eles tinham; (b) auxiliá-los a entender mais sobre os modos em que algumas dessas crenças criavam impasses no seu conhecimento do passado; e (c) oferecer-lhes alguns novos modos de pensar o conhecimento histórico e justificações alegadamente históricas que poderiam ajudá-los a superar esses impasses. Tal curso, esperávamos, daria oportunidades para futuros professores de história trazer à superfície suas opiniões epistêmicas através de investigação e reflexão. Lutar com essas ideias complexas e engajar em atividades epistemologicamente desafiadoras, nós teorizamos adicionalmente, poderiam permitir aos alunos a oportunidade de entender os limites cognitivos de suas crenças. Esperávamos que, neste curso, eles pudessem encontrar significado e utilidade em crenças epistêmicas mais poderosas, associadas com o tipo de pensamento histórico e de habilidades de julgamento que cultivam entendimentos mais profundos do passado. Fazer isso, imaginávamos, poderia capacitá- 
los a fortalecer as suas capacidades pedagógicas uma vez que que eles encontrassem a si próprios em posições semelhantes à de Danielle.

\section{Método}

\section{Um "Ensino de introdução à história"}

Num esforço para lidar com as questões epistêmicas que os professores de história que observamos pareciam estar enfrentando, o primeiro autor esboçou o currículo para o curso. Com a cooperação do departamento de história da universidade, ele ofereceu o curso para veteranos de história duas vezes em dois semestres consecutivos numa universidade com grande público nos EUA. O curso tinham um encontro semanal (14 encontros) de 75 minutos. Os alunos se matricularam voluntariamente e ganhariam um crédito se terminassem o curso satisfatoriamente. Isto envolvia completar vários questionários e outras tarefas, incluindo a construção de dois esboços de plano de aula, leitura de textos indicados e participar ativamente das discussões em sala de aula, as quais consistiam em dar sentido aos impasses cognitivos e encontrar os meios de resolvê-los.

Em resumo, o curso começou levantando questões epistêmicas tais como: O que é a história, qual é a diferença entre história e o passado, de onde vêm as histórias, qual é a diferença entre um fato e uma opinião, e o que constitui uma interpretação ou um argumento históricos que são baseados em evidência? As questões foram discutidas tanto diretamente quanto por meio de exercícios que envolviam ler relatos conflitantes de eventos históricos (por exemplo, o que aconteceu na batalha de Little Big Horn?) ou sobre indivíduos (por exemplo, quem foi Abraham Lincoln, o Grande Emancipador, ou...?). A ementa para cada curso era a mesma, salvo que os exemplos dos períodos históricos eram diferentes, para refletir o foco na história americana anterior a 1865 na primeira versão do curso, e posterior a 1865 na segunda versão. O curso envolvia usar um conjunto de estratégias de ensino-aprendizagem que fossem produzidas para trazer à tona as crenças epistêmicas dos matriculados e trazê-las à consideração e discussão. O curso ajudava-os então a identificar as crenças que criavam impasses cognitivos do tipo das que Danielle tinha. Finalmente, o curso fornecia ideias e estratégias concretas para 
desenvolver a hermenêutica pragmática de Kloppenberg (1989) com base na pressuposição de que ao fazer isso os alunos seriam ajudados a ir além desses impasses e seriam capacitados a fazer o mesmo com seus futuros alunos.

\section{Participantes}

O grupo consistia em 18 alunos. O primeiro grupo de 11 alunos frequentou a primeira série de aulas e o segundo grupo de sete alunos frequentou a segunda. Em cada curso, os alunos compunham uma gama de calouros (3 de 18), alunos de segundo ano (6), de terceiro (7) e de quarto ano (2). Todos, com exceção de três, declararam cursar história e três dos 18 história/educação. Quatro alunas - Genevieve, Lily, Josie e Michaela -, duas de cada turma, concordaram em ser entrevistadas com mais profundidade sobre suas crenças epistêmicas com relação ao instrumento escala Likert, que avalia essas crenças e a natureza da experiência do curso no que diz respeito elas.

\section{Medição Primária}

Usamos o Questionário de Crenças sobre História (QCH) para explorar especificamente e coletar dados sobre as crenças epistêmicas dos alunos sobre a história. Este questionário de escala Likert, com 6 pontos e 22 itens (ver o Apêndice), é um refinamento de uma medição cuja estrutura de fato foi investigada, testada e validada em estudos anteriores (MAGGIONI ET AL. 2004; MAGGIONI ET AL. 2009). Suas afirmações foram formuladas para refletir diferentes conceituações da natureza do conhecimento histórico e exemplificar crenças que caracterizavam três posições epistêmicas teoricamente deduzidas da literatura sobre o conhecimento epistêmico (e.g., KING \& KITCHENER, 2002; KUHN \& WEINSTOCK, 2002) e o pensamento histórico (e.g., LEE \& SHEMILT, 2003; VANSLEDRIGHT, 2011; WINEBURG, 2001).

Em particular, algumas das afirmações refletem as crenças em uma visão da história sem autor, simplisticamente concebida como "o que foi" (por exemplo, "Os fatos falam por si."). Um acordo consistente sobre tais itens, nós teorizamos, reflete o que 
poderíamos chamar de a forma de um realismo ingênuo ou o que começamos a chamar de objetivismo, no qual a história é entendida como uma mera cópia do passado. Esta posição poderia ser relacionada com a versão ingênua da ideia de Kloppenberg (1989) de “objetividade científica” em história.

Outras afirmações sinalizam que a história pode tornar-se fundamentalmente subjetiva porque o passado se torna visível para nós principalmente (somente?) através das vozes de testemunhas e historiadores (por exemplo, "O passado é o que o historiador faz que ele seja”). Um acordo consistente com tais afirmações, de novo a partir de nossa teorização baseada na literatura, sugere uma posição de subjetivismo ingênuo, pelo menos no modo como os itens são nomeados no QCH. Numa forma extrema, seria em alguns aspectos similar ao que Kloppenberg (1989) chama de "relativismo completo."

Finalmente, um terceiro grupo de afirmações reflete a consciência de que a história resulta de um processo de investigação: a história emerge de uma interação entre o historiador (o conhecedor) e suas questões e o arquivo, ou o que está por saber (por exemplo, "Relatos razoáveis podem ser construídos até mesmo em presença de evidência conflitante.”). Esta posição envolve saber algo sobre os critérios para disciplinar o processo de investigação e produzir histórias defensáveis. Baseados, mais uma vez, em nossa teorização, poderíamos fazer referência a uma pessoa que concordaria consistentemente com tais afirmações como um adepto do criterialismo (a hermenêutica pragmática de Kloppenberg). Descrevemos como chegamos a, e como definimos, cada uma dessas posições epistêmicas no QCH com mais detalhes abaixo.

\section{Procedimentos}

Os participantes responderam às afirmações do QCH duas vezes, uma vez bem no início e outra no fim do semestre. Eles responderam ao QCH basicamente por escrito. A primeira aplicação do QCH aconteceu no primeiro dia de curso e a segunda no último dia de cada versão do semestre. Depois que os alunos completaram o QCH a segunda vez, eles receberam a versão inicial e tiveram de analisar as mudanças nas suas respostas. 
Para cada item sobre o qual a sua posição tinha mudado (para maior ou menor concordância/discordância), pediu-se que identificassem a afirmação por número e explicassem por escrito por que a sua posição tinha mudado. Às quatro informantes principais - Genevieve, Lily, Josie e Michaela - que foram entrevistadas (pelo segundo autor), pediu-se que discutissem em maior profundidade tais mudanças, acrescentando ou explicando mais o que tinham escrito. Identificamos essas quatro alunas perto do começo de cada série de aulas com base em contrastes inter-relacionados no histórico (interesse declarado na disciplina, raça/etnia na medida do possível, fase universitária) e nas suas respostas iniciais ao $\mathrm{QCH}$. O segundo autor, que esteve presente nas aulas mas não participou diretamente senão fazendo anotações das atividades de aula, entrevistouas várias vezes ao longo de cada semestre no qual elas estavam matriculadas.

\section{Análise dos dados}

Dados do QCH. Apoiamo-nos inicialmente num conjunto de estudos anteriores para teorizar os códigos que usaríamos para começar a analisar e entender os dados do QCH. Os três com que começamos foram o copier, o borrower e o criterialist (MAGGIONI ET AL., 2004; 2009, MAGGIONI ET AL., 2009). Um processo iterativo de análise no qual discutimos novas categorias para representar aspectos que emergiam dos dados que não foram previamente descritos na literatura e controlar as rubricas revisadas a partir dos dados, até que a maior parte dos dados pudesse ser codificada de acordo com as rubricas e nenhum novo aspecto emergisse. Assim, usamos tanto a dedução de princípios quanto a indução a partir dos dados no desenvolvimento das três categorias refinadas, objetivismo, subjetivismo e criterialismo.

A fim de dar validade às três categorias, notamos que eram de modo geral compatíveis com os modelos epistêmicos de desenvolvimento de Kuhn e Weinstock (2002) e King e Kitchner (2002), casando-os com a trajetória de desenvolvimento dos conceitos de passado, evidência e relatos históricos descritos no trabalho de Lee e seus colegas (LEE, 2004; LEE \& ASHBY, 2000; LEE \& SHEMILT, 2003). Em particular, seguindo Kuhn e Weinstock, achamos útil caracterizar as diferentes crenças epistêmicas num 
independente e adicional com outro colega seu para validar ainda mais as três categorias e o contínuo em que caíram (ver MAGGIONI et al., 2009).

Numa das extremidades do contínuo objetivo-subjetivo, a primeira categoria, o objetivismo, descreve uma visão ingênua do conhecimento em que não há uma consciência geral do papel do conhecedor. Lee e Shemilt (2003) descreveram uma posição semelhante: Restos do passado são concebidos como fatos brutos, garantindo acesso imediato ao passado; o papel da argumentação ao decidir quais restos contam como evidência não é reconhecido e impasses eventuais (por exemplo, conflitos insolúveis entre diferentes relatos) são condenados pela incorreção da "informação". $\mathrm{Na}$ melhor das hipóteses, nesta visão, é confiada aos investigadores a tarefa de discriminar entre artefatos e testemunhas verdadeiros ou falsos, e de reportar fielmente a história sem adulteração contada por esses restos objetivos, como na noção de von Rankean de deixar o passado falar com suas próprias palavras.

Do outro lado do objetivismo epistêmico está o subjetivismo. No caso do subjetivista, o papel do conhecedor é percebido, com frequência ingenuamente entre os novatos, como predominante e no mais das vezes, desligado ou livre de qualquer referência a algo que exista fora do conhecedor; assim, o papel da evidência na construção de argumentos não é tipicamente reconhecido ou às vezes entendido como opinião. Esta ideia encontra eco no trabalho de Lee (2004), em que ele reportou que alguns alunos explicavam as diferenças nos relatos como um "problema do autor", devido a erros ou diferenças de pontos de vista e ao "problema do viés." No presente estudo, afirmações que refletem essas crenças revelaram questões de opinião e/ou viés pessoal, e raramente mencionaram a dificuldade de discriminar diferentes testemunhos. Crenças relativistas (ver KLOPPENBERG, 1989), pressentíramos, estavam na raiz desta posição.

Duas categorias adicionais emergiram da nossa análise indutiva-dedutiva. A primeira descreve as tentativas muitas vezes epistemicamente acidentadas e 
TR2), porque os alunos pareceram oscilar entre os argumentos e as ideias que caracterizam os dois extremos (posições objetivistas e subjetivistas), frequentemente nas suas explicações das mudanças em posições epistêmicas na segunda aplicação do QCH. Esses alunos permaneceram incapazes de produzir uma síntese harmônica entre conhecedor e conhecido e de superar os impasses cognitivos que tais posições frequentemente criaram.

Afirmações que exprimem a posição epistêmica nomeada de TR1 deram voz ao desejo ardente de que a história simplesmente coincidisse com o passado. Em outras palavras, os investigadores da história eram vistos como alguém que deseja ser um cronista, compartilhando assim muito da posição objetivista. Contudo, essas afirmações exprimiram simultaneamente a consciência de que o conhecimento sólido do passado é sempre, ou pelo menos muito frequentemente, impossível porque a interpretação do que deixamos de fora do passado pode ser transformado em dado ou porque simplesmente ficamos com muito pouco. Nesses casos, e de certo modo lamentavelmente, os entrevistados escorregavam então para descrições da história como um esforço inevitavelmente subjetivo, e ela se tornava apenas uma questão de opinião, refletindo muitas das ideias que caracterizam a posição subjetivista. Contudo, contrariamente a uma posição subjetivista mais consistente, essas afirmações exprimiram o lamento dos participantes em relação a essas ocorrências, e também a crença de que isto não deveria ser uma condição universal do conhecimento histórico e produziram uma clara dicotomia entre fatos e opiniões no esforço de desfazer o seu sentimento de espanto e evitar os impasses que a aderência a crenças relativísticas criou. Os alunos que refletem posições TR1 pareciam ser objetivistas exaustos, desencorajados pelo fato de que, em história, de qualquer modo, as coisas pareciam tais que erro e viés demais se insinuavam para que o conhecimento definitivo e objetivo fosse possível. E isso redundava na perda de todos. Talvez, eles pareciam pensar, nós precisássemos fazer tentativas mais sérias para chegar ao fundo da questão, sem saber como. 
Em contraste, TR2 sinaliza um movimento mais evidente em direção da harmonização entre objeto do conhecimento e sujeito da geração do conhecimento, e é expresso por declarações que reconhecem que a história é um trabalho interpretativo do conhecedor baseado em evidência (algo que TR1 não reconhece). Contudo, estas declarações também indicam uma falta relativamente profunda de clareza sobre métodos, critérios ou julgamentos que permitiriam tal harmonização. Em outras palavras, embora tais informantes parecessem entender a necessidade de criterialismo (uma hermenêutica pragmática), eles simplesmente não estavam certos de onde consegui-lo e de como ir atrás dele. Efetivamente, eles permaneciam imobilizados.

O último passo no contínuo visualizado nos modelos de Kuhn e Weinstock (2002) e King e Kitchener (2002), e também implicado por Lee (2004), envolve a harmonização dos aspectos objetivo e subjetivo do conhecimento, uma posição representada pelo que chamamos e codificamos como criterialismo. Os indivíduos que compartilham esta posição reconheceriam o papel interpretativo do conhecedor na escolha e avaliação dos residua do passado. Nos termos de Lee (2004), esses indivíduos reconheceriam que as diferenças nos relatos dependem da natureza mesma dos relatos históricos. Contudo, eles também reconheceriam que tal trabalho interpretativo se apoia em critérios específicos e heurísticos que caracterizam o método histórico. Por exemplo, este método permite ao investigador transformar os restos do passado em evidência, fazendo perguntas a relatos históricos que eles não pretendiam necessariamente responder e colocando-os no seu contexto histórico. Garantir, então, alegações históricas requer um exame cuidadoso de relatos disponíveis por meio de perguntas que um investigador faz, um processo sistemático de corroboração de processo que resulta na preponderância da evidência - um critério-chave ao fazer alegações sobre um conhecimento, um esforço para apoiar as alegações fazendo tal evidência transparente via citação, e subsequente verificação por peer review.

O criterialista também entende que, quando a evidência é fraca ou inexistente, um grau de imaginação subjetivista é requerido para juntar as alegações históricas. Portanto, um apoio mais objetivista na evidência pode ser integrado com elementos subjetivistas numa harmonização racionalmente exitosa de crenças, animada por ideias fortes sobre 
como conduzir tal integração de modo que seja aceitável aos outros que compartilham as mesmas crenças epistêmicas gerais. Tal harmonização resolve impasses cognitivos que infestam o objetivista (ingênuo), que não sabe como reconciliar os relatos conflitantes, e o subjetivista (ingênuo), que não possui nenhum critério para distinguir um relato histórico defensável de outro que o é menos. Como resultado, a posição criterialista permite que a história se torne de novo factível (ver LEE, 2004).

Ao analisar as crenças epistêmicas dos alunos, tivemos que nos apoiar grandemente nas suas respostas aos itens do QCH e nas suas explicações escritas sobre as suas ideias que mudaram. Devido às limitações de recursos, pudemos entrevistar apenas as quatro alunas mencionadas mais extensamente sobre as mudanças nas suas respostas ao QCH. Como resultado, desenvolvemos um método para pesar as respostas da escala Likert de 6 itens no QCH. A ideia era medir a magnitude da mudança entre o précurso ao pós-curso, como um meio de ver o movimento entre os alunos que o experimento do curso estava tentando provocar. Isto, por sua vez, pensávamos nós, poderia lançar luz obre como codificar melhor as posições pós-curso dos alunos no contínuo categorial e ajudar a entender melhor os comentários escritos registrados e as explicações das quatro entrevistadas. Esta abordagem estava sustentada por uma posição teórica que estipulava que a consistência da resposta através dos itens de uma categoria particular (objetivismo, subjetivismo, criterialismo) sinalizaria uma aderência razoavelmente segura àquela crença. Variações regulares em respostas, por outro lado, sinalizariam mais adequadamente uma posição transicional. Ao classificar as respostas, houve três questões que precisamos resolver. A primeira tinha a ver com o peso.

A escala Likert do QCH contém 6 níveis de concordância/discordância: concorda fortemente (6), concorda (5), concorda um pouco (4), discorda um pouco (3), discorda (2) e discorda fortemente (1). Para medir esta variação, classificamos as respostas dos 18 alunos usando as seguintes equivalências: $6=+3 ; 5=+2 ; 4=+1 ; 3=-1 ; 2=-2$; e $1=-3$ (Variação: concorda fortemente $=+3$ a discorda fortemente $=-3$ ).

O segundo dizia respeito aos tipos dos itens. Identificamos duas subescalas no QCH para ajudar a diferenciar o entendimento dos resultados (de acordo com BUEHL \& ALEXANDER, 2001). Fazer isso exigiu a rotulação dos itens em virtude de que tipo das três 
posições eles tencionavam mostrar teoricamente por subescala. As duas subescalas foram identificadas como (a) itens formulados para mostrar crenças sobre a história epistêmicas como uma disciplina ou um tópico. Rotulamo-la como História, ou H; compreendeu 13 itens. A outra subescala mostrou crenças sobre o ensino e a aprendizagem de história. Abreviamos como EAH; constituiu-se de 9 itens. As respostas de cada aluno nas duas subescalas foram avaliadas separadamente usando a variação de classificação de +3 até -3 .

Na subescala $\mathrm{H}$, há 5 itens que medem as respostas da categoria criterialismo, 3 sobre as respostas do objetivismo e 5 sobre as respostas do subjetivismo. Na subescala $\mathrm{EAH}$, há 4 itens que medem as respostas do criterialismo, 2 sobre as respostas do objetivismo e 3 sobre as respostas do subjetivismo. Para ilustrar a classificação de subescalas e das categorias dentro delas, imagine que o Aluno A circulou 4, 6, 2, 5 e 5 respostas Likert nos cinco itens do criterialismo que avaliam aquela posição na subescala H. Em peso isso significa $+1,+3,-2,+2$ e +2 respectivamente, para um total aditivo de +6 . Uma vez que há 5 itens nesta categoria de subescala, dividimos +6 por 5 para chegar à classificação de +1.2 (de um máximo de classificação de concordância/discordância de +3/3). Ao interpretar tal classificação, gostaríamos de caracterizar como "fraca concordância" com a categoria de criterialismo por causa da sua grande proximidade ao 4 (concorda um pouco, ou peso +1) na escala Likert. Empregamos esse procedimento com cada subescala e categoria dentro delas para chegar a classificações em categorias ao longo das duas subescalas.

A terceira questão envolveu desenvolver uma classificação consistente. Para avaliar um sentindo de consistência geral, estávamos mais interessados no grau em que as respostas se alinhavam à posição de criterialismo, uma vez que isto era o alvo pretendido do curso universitário. Criamos uma razão (expressa em porcentagem) de respostas objetivistas e subjetivistas a respostas criterialistas. Por exemplo, se um aluno estivesse em acordo $(+1,+2$ ou +3$)$ com todos os itens criterialistas e em desacordo $(-1,-2$ ou -3) sobre todos os itens objetivistas e subjetivistas, haveria uma classificação de $100 \%$ de consistência. Uma vez que estávamos verificando aqui o grau de consistência com as crenças criterialistas, o método mais rápido para calcular a classificação de consistência 
era ler as respostas Likert dos alunos e identificar quantas daquelas respostas exprimiam discordância com itens criterialistas e concordância com itens objetivistas e subjetivistas no QCH. Totalizando-as com "discordâncias com o criterialismo", subtraindo-as do número total de itens (22) e então dividindo por 22, chegamos à classificação final de consistência (e.g, 22 itens totais menos 5 respostas inconsistentes $=17 / 22$ ou $77 \%$ ).

A fim de codificar o resultado total das respostas dos alunos pela categoria de crença, empregamos duas teorias baseadas nas análises iterativas desses dados. Primeiro, olhares mudam com o tempo. Se, dados os seus pretendidos objetivos de desenvolvimento criterialista, o curso fosse exitoso para um dado aluno, classificações criterialistas cresceriam enquanto as classificações objetivistas e subjetivistas iriam decrescer. A segunda teoria aqui era que para ser um criterialista, dever-se-ia precisar de uma classificação acima da média de +2.5 (chegando perto de concordar fortemente) nos itens criterialistas (tanto na subescala $H$, quanto na EAH) e uma classificação negativamente (isto é, em desacordo) acima de, pelo menos, uma média de -2.0 (desacordo) em todos os itens objetivistas e subjetivistas.

Esta é uma faixa epistêmica alta, mas em nossas análises tínhamos teorizado uma faixa alta o tempo todo como resposta a comentários de historiadores experientes sobre a validade da escala (MAGGIONI et al., 2009), possíveis efeitos de forte desejabilidade social por itens criterialistas, e, de modo relacionado, estudos anteriores (por exemplo, KING \& KITCHENER, 2002) em que os participantes selecionaram respostas mais fortes e mais positivas nos itens de tipo criterialista do que os seus argumentos nas repostas orais subsequentes poderiam justificar. Para auxiliar no processo de manter a faixa de categorização alta, uma classificação de consistência também foi calculada com base nas respostas a todos os 22 itens. Defendemos que a consistência é um traço-chave pois é capaz de avaliar as posições. Usamos uma classificação de consistência em ou acima de 90\% como uma garantia da consistência com crenças criterialistas no QCH necessária para sinalizar uma posição criterialista razoavelmente sólida e estável.

Entrevistas. Para aumentar este processo, analisamos os dados das entrevistas das quatro alunas e os comentários escritos de 18. Em vez de codificar e categorizar esses dados qualitativos, usamo-los para ajudar a substanciar o processo de codificação do QCH 
apenas descrito. Se, por exemplo, os dados qualitativos sugerissem que as nossas análises do QCH eram imprecisas porque um aluno particular forneceu um argumento ou justificativa que o anulasse, ajustaríamos a nossa categorização para se enquadrar ao argumento ou justificativa dada. Contudo, esses ajustes foram raros. Os dados qualitativos deram suporte às codificações do $\mathrm{QCH}$, provavelmente em razão das estritas faixas que estabelecemos para impor a categorização de uma rubrica.

\section{Resultados e Interpretações}

Começamos pela apresentação dos resultados das nossas análises dos dados do QCH, especificamente como alunos se classificaram nos itens da escala Likert pré-curso e pós-curso, e como categorizamos as respostas nas cinco categorias que descrevemos. Faremos isso por subescala. Também mostraremos as classificações de consistência para cada aluno. Daremos em seguida uma descrição dos resultados que surgiram dos nossos dados das entrevistas com as quatro alunos, duas do primeiro curso (Genevieve, Lily) e duas do segundo (Josie, Michaela).

\section{O posicionamento epistêmico dos alunos}

Antes de apresentar os resultados, seria útil conhecer melhor o contexto e o histórico dos 18 alunos. A Figura 2 fornece um sumário de vários aspectos deste histórico. 15 dos 18 tinham declarado a história como seu campo de interesse. Tipicamente, no seu segundo ou terceiro ano nesta universidade, os alunos de história fazem um curso de métodos de pesquisa básica, no qual eles aprendem como conduzir uma pesquisa histórica, que ferramentais são necessárias e com quais critérios gerais da disciplina elas são aplicadas, e como construir um relato histórico curto (uma tese/argumento, alegações evidenciais, citações) com base em uma questão e algumas investigações em relação àquela questão. Doze dos 18 tinham feito este curso ou estavam fazendo. Estando no segundo ou terceiro ano, 13 (72\%) estavam no meio da sua experiência universitária. Dois alunos - Lily e Hannah - tinham declarado o seu forte interesse em 
história. Xavier, um aluno de geografia, era o único aluno que veio ao curso de fora da história e/ou educação. Todos os alunos eram descendentes de europeus, exceto Genevieve, que era descendente de asiáticos, Lily, que era afrodescendente e Adam, que era descendente de paquistaneses. Os alunos escolheram seus próprios pseudônimos.

Figura 2. Dados dos históricos dos 18 alunos universitários

\begin{tabular}{|c|c|c|c|c|c|c|c|}
\hline \multicolumn{4}{|l|}{ Turma $1(n=11)$} & \multicolumn{4}{|c|}{ Turma $2(n=7)$} \\
\hline Name* & Curso & Ano & $\begin{array}{l}\text { Métodos } \\
\text { de } \\
\text { Pesquisa }\end{array}$ & Name* & Curso & Ano & $\begin{array}{l}\text { Métodos } \\
\text { de } \\
\text { Pesquisa }\end{array}$ \\
\hline Genevieve** & História & 4 & Sim & Josie* & História & 3 & Sim \\
\hline Lily** & Educ & 1 & Não & Michaela* & História & 3 & Sim \\
\hline Brittney & Hist/Educ & 2 & Sim & Adam & História & 2 & Sim \\
\hline Lolly & Hist/Educ & 3 & Sim & Lyla & Hist/Educ & 3 & Sim \\
\hline Xavier & Geografia & 4 & Não & Katie & História & 1 & Não \\
\hline Rizza & Història & 2 & Não & Nesa & História & 2 & Não \\
\hline Alan & Govr/Hist & 3 & Sim & Jaya & História & 2 & Sim \\
\hline Hannah & Educ & 1 & Não & & & & \\
\hline Bob & História & 3 & Sim & & & & \\
\hline Jacoby & História & 3 & Sim & & & & \\
\hline Derick & História & 2 & Sim & & & & \\
\hline
\end{tabular}

Totais $=2$ de $4^{\circ}, 7$ de $3^{\circ}, 6$ de $2^{\circ}, 3$ de $1^{\circ}$

* Todos os nomes são pseudônimos

** Casos pesquisados com maior profundidade.

O quadro 1 retrata os resultados das análises das respostas dos alunos às duas aplicações dos itens do QCH por categoria e subescala, indica classificações comparativas de consistência e mostra a codificação das posições epistêmicas dos alunos relativas à alta faixa que tínhamos estabelecido. Os itens do QCH que mostravam posições em uma categoria particular são mostrados em parênteses no alto de cada coluna sob a abreviação da categoria. O número que é colocado ao lado do nome de cada aluno representa ou os resultados da administração do QCH pré-curso (1) ou os resultados póscurso (2).

De modo geral, mais de $75 \%$ dos alunos começaram numa fase epistêmica transicional e permaneceram nela apesar das suas experiências no curso. Com base na análise das mudanças de classificação por peso, alguns alunos (por exemplo, Rizza, Bob, Josie, Lyla) pareciam externar algumas questões epistêmicas na direção de se tornarem 
mais criterialistas nas suas inclinações, enquanto outros ficaram mais perplexos sobre os seus posicionamentos epistêmicos.

Quadro 1. Classificações por peso de Categorias Epistêmicas, Classificações de Consistência e Codificações por Alunos e Turma

\begin{tabular}{|c|c|c|c|c|c|c|c|c|c|}
\hline $\begin{array}{l}\text { Aluno } \\
\text { Turma } 1\end{array}$ & $\begin{array}{l}\begin{array}{l}\text { Crite- } \\
\text { rialismo } \\
(3,11,13 \\
18,21)\end{array}\end{array}$ & $\begin{array}{l}\text { Obje- } \\
\text { tivismo } \\
(5,16,19)\end{array}$ & $\begin{array}{l}\text { Subje- } \\
\text { tivismo } \\
(2,8,12, \\
14)\end{array}$ & $\begin{array}{l}\text { Codifi- } \\
\text { cação }\end{array}$ & $\begin{array}{l}\text { Crite- } \\
\text { rialismo } \\
(1,7,15, \\
17)\end{array}$ & $\begin{array}{l}\text { Obje- } \\
\text { tivismo } \\
(9,20)\end{array}$ & $\begin{array}{l}\text { Subje- } \\
\text { tivismo } \\
(4,6,10)\end{array}$ & $\begin{array}{l}\text { Codifi- } \\
\text { cação }\end{array}$ & $\begin{array}{l}\text { Classi- } \\
\text { ficação } \\
\text { de } \\
\text { Consis- } \\
\text { tência }\end{array}$ \\
\hline Genev. 1 & +2.7 & -2.7 & +1 & TR2 & +2.75 & +1 & -.5 & TR1 & $77 \%$ \\
\hline Genev. 2 & +2.0 & -1.0 & +1.2 & TR2 & +3.0 & 0 & +.67 & TR2 & $64 \%$ \\
\hline Lily 1 & +2.2 & -1.3 & -1.4 & TR2 & +1.5 & -2.0 & -1.0 & TR2 & $86 \%$ \\
\hline Lily 2 & +1.8 & -1.0 & -.2 & TR2 & +1.8 & -2.5 & -.67 & TR2* & $82 \%$ \\
\hline Brittn. 1 & +1.6 & 0 & +.4 & TR1 & +1.75 & +1.0 & -1.67 & TR1 & $65 \%$ \\
\hline Brittn. 2 & +2.4 & -.67 & +1.0 & TR2 & +3.0 & -2.5 & +1.0 & TR2 & $80 \%$ \\
\hline Lolly 1 & +1.0 & -.33 & -.60 & TR2 & +1.75 & +1.0 & 0 & TR1 & $71 \%$ \\
\hline Lolly 2 & +1.4 & -.67 & -.20 & TR2 & +2.5 & 0 & -1.0 & TR2 & $77 \%$ \\
\hline Xavier 1 & +1.0 & 0 & +2.0 & Subj. & +1.25 & 0 & -1.0 & TR1 & $55 \%$ \\
\hline Xavier 2 & +2.6 & +1.33 & -.20 & TR1 & +2.75 & +1.0 & -.33 & TR1 & $64 \%$ \\
\hline Rizza 1 & +.80 & -.67 & +.40 & TR1 & +1.0 & -2.5 & +1.33 & Subj. & $60 \%$ \\
\hline Rizza 2 & +1.0 & -2.67 & -.80 & TR2 & +2.5 & -2.5 & +.67 & TR2 & $90 \%$ \\
\hline Alan 1 & +2.2 & -1.67 & -1.2 & TR2 & +1.0 & -2.0 & -1.67 & TR2 & $86 \%$ \\
\hline Alan 2 & +2.2 & -2.33 & 0 & TR2 & +2.5 & -3.0 & -2.0 & TR2* & $86 \%$ \\
\hline Hanna.1 & +2.0 & +1.33 & +.80 & TR1 & +2.0 & +2.0 & +1.33 & TR1 & $50 \%$ \\
\hline Hanna.2 & +1.8 & -.33 & +1.2 & TR2 & +2.75 & +1.0 & +1.0 & TR1 & $59 \%$ \\
\hline Bob 1 & +1.6 & -2.33 & -2.0 & TR2 & +1.0 & -2.5 & -2.0 & TR2 & $95 \%$ \\
\hline Bob 2 & +1.6 & -2.67 & -2.2 & $\begin{array}{l}\text { Crite- } \\
\text { rialista } \\
\text { fraco? }\end{array}$ & +1.0 & -2.5 & -2.67 & $\begin{array}{l}\text { Crite- } \\
\text { rialista } \\
\text { fraco? }\end{array}$ & $95 \%$ \\
\hline Jacoby1 & +1.4 & -.33 & -2.2 & TR2 & +.75 & -.5 & -2.0 & TR2 & $86 \%$ \\
\hline Jacoby2 & +1.6 & -1.0 & -2.2 & TR2 & +1.75 & -3.0 & -1.67 & TR2 & $77 \%$ \\
\hline Derick 1 & +1.4 & -.75 & -2.0 & TR2 & +1.25 & -2.5 & -2.0 & TR2 & $86 \%$ \\
\hline Derick 2 & +2.2 & -2.0 & -1.8 & TR2 & +1.5 & -1.5 & -1.33 & TR2 & $86 \%$ \\
\hline
\end{tabular}




\section{Turma 2 rialismo \\ Obje- \\ Subje- $(3,11,13, \quad(5,16,19) \quad(2,8,12$, $18,21)$ \\ 14)}

Codifi-

Crite-

Classi-

Josie 1

$+2.0$

$-1.33$

$-2.2$

Crite-

$(1,7,15, \quad(9,20) \quad(4,6,10)$

17)

rialista

$+2.5$

$-2.0$

$-1.0$

Crite-

rialista

fraco?

Josie $2+3.0$

$-2.0$

$-1.2$

Crite-

$+2.75$

$-3.0$

$-.67$

fraco?

rialista

Crite-

$86 \%$

modera

rialista

do

modera

do

$\begin{array}{lccc}\text { Micha. 1 } & +1.6 & -1.33 & -1.0 \\ \text { Micha. 2 } & +1.4 & -1.33 & -.80 \\ & & & \\ \text { Adam 1 } & +1.4 & +.33 & +.20 \\ \text { Adam 2 } & +2.0 & 0 & -.20 \\ & & & \\ \text { Lyla 1 } & +1.6 & -2.0 & -.80 \\ \text { Lyla 2 } & +2.6 & -2.33 & -2.2\end{array}$

$\begin{array}{lll}\text { TR2 } & +2.0 & -2.0 \\ \text { TR2 } & +2.0 & -2.0 \\ & & \\ \text { TR1 } & +2.5 & +2.0 \\ \text { TR2 } & +2.5 & -2.5 \\ & & \\ \text { TR2 } & +1.25 & -2.0 \\ \text { Crite- } & +1.5 & -2.5 \\ \text { rialista } & & \end{array}$

$-.67$

TR2

$86 \%$

80

$-2.0$

TR2

$82 \%$

$+2.0$

$+2.33$

TR1

$55 \%$

20

$-2.5$

$-1.0$

TR2

$73 \%$

-2.0
-2.5

$-.33$

TR2

$73 \%$

$-1.33$

Crite-

$86 \%$

rialista

fraco

$\begin{array}{lccccccccc}\text { Katie 1 } & +1.2 & -.33 & -.4 & \text { TR2 } & +.75 & -1.5 & -.33 & \text { TR2 } & 68 \% \\ \text { Katie 2 } & +2.0 & +1.0 & -.2 & \text { TR1 } & +1.75 & -2.0 & +.33 & \text { TR2 } & 68 \% \\ & & & & & & & & & \\ \text { Nesa 1 } & +2.0 & +.33 & -1.0 & \text { TR1 } & +1.75 & 0 & -.33 & \text { TR1 } & 73 \% \\ \text { Nesa 2 } & +1.6 & -.33 & -.20 & \text { TR2 } & +2.0 & -1.0 & -.67 & \text { TR2 } & 73 \% \\ & & & & & & & & & \\ \text { Jaya 1 } & +1.8 & -.67 & -1.2 & \text { TR2 } & +1.75 & -2.0 & -1.33 & \text { TR2 } & 91 \% \\ \text { Jaya 2 } & +1.6 & 0 & -1.2 & \text { TR2 } & +1.0 & -2.0 & -.67 & \text { TR2 } & 77 \%\end{array}$

TR1 ou TR2 representam uma das categorias transicionais. Chamamos esses alunos de hesitantes. TR2* = Possivelmente um criterialista muito fraco. EBCr? = Provavelmente um criterialista fraco, embora as classificações não estejam completamente além das faixas altas estabelecidas, apesar de se aproximarem muito delas.

Contudo, outro modo de representar os dados revela um padrão que mostra que o curso de fato ajudou a mover os alunos de maneira geral a ajustar as suas posições de modo que se afastassem das posições que criavam impasses para eles e na direção de orientações criterialistas mais fortes. Se o objetivo do curso era - em termos do QCH aumentar as classificações positivas dos itens criterialistas e aumentar as classificações negativas dos itens objetivistas e subjetivistas como uma representação de mudanças nas 
crenças epistêmicas, então podemos mostrar classificações deste modo procurando na tabela 1 tais exemplos e contando a diferença entre o pré-curso e o pós-curso em cada categoria. Ademais, podemos inverter este método comparando quantas reduções houve em respostas ambivalentes (isto é, média em zero) e positivas aos itens objetivistas e subjetivistas da administração pré-curso do QCH ao pós-curso, e também quantas classificações negativas apareceram nos itens criterialistas do pré-curso ao póscurso. O quadro 2 mostra essas duas diferentes relações de frequência.

\begin{tabular}{|c|c|c|c|c|}
\hline & $\begin{array}{l}\text { QCH pré-curso } \\
\text { Número de } \\
\text { casos }\end{array}$ & $\begin{array}{l}\text { QCH pós-curso } \\
\text { Número de casos }\end{array}$ & $\begin{array}{l}\text { Mudança } \\
\text { total }\end{array}$ & $\begin{array}{l}\text { Direção da mudança } \\
\text { epistêmica }\end{array}$ \\
\hline $\begin{array}{l}\text { Faixa alta }(\geq+2.5) \\
\text { Classif. Criter. }\end{array}$ & 1 & 6 & +5 & $\begin{array}{l}\text { Aumento em direção do } \\
\text { objetivo do curso }\end{array}$ \\
\hline $\begin{array}{l}\text { Faixa alta }(>-2.0) \\
\text { Classif. Objet. }\end{array}$ & 3 & 9 & +6 & $\begin{array}{l}\text { Aumento em direção do } \\
\text { objetivo do curso }\end{array}$ \\
\hline $\begin{array}{l}\text { Faixa alta }(>-2.0) \\
\text { Classif. Subjet. }\end{array}$ & 2 & 3 & +1 & $\begin{array}{l}\text { Aumento em direção do } \\
\text { objetivo do curso }\end{array}$ \\
\hline Totais & 6 & 18 & +11 & \\
\hline $\begin{array}{l}\text { Mais ou Zeros } \\
\text { Classif. Objet. }\end{array}$ & 6 & 7 & +1 & $\begin{array}{l}\text { Aumento afastando-se do } \\
\text { objetivo do curso }\end{array}$ \\
\hline $\begin{array}{l}\text { Mais ou Zeros } \\
\text { Classif. Subjet. }\end{array}$ & 6 & 6 & $\begin{array}{l}\text { Não houve } \\
\text { mudança }\end{array}$ & $\begin{array}{l}\text { Nenhuma redução para o } \\
\text { objetivo do curso }\end{array}$ \\
\hline $\begin{array}{l}\text { Menos ou Zeros } \\
\text { Classif. Criter. }\end{array}$ & 0 & 0 & $\begin{array}{l}\text { Não houve } \\
\text { mudança }\end{array}$ & \\
\hline Totais & 12 & 13 & +1 & \\
\hline
\end{tabular}

Os padrões sugerem aqui que o curso teve como efeito alguma influência em afastar os alunos das crenças objetivista e subjetivista que tendiam a criar impasses cognitivos para eles quando tentavam entender a história e como ela poderia ser melhor ensinada, mas de modos algo imprevisíveis. Por exemplo, dos seis alunos que tinham classificações de criterialismo, objetivismo e subjetivismo de faixa alta no QCH1, três mantiveram ou aumentaram as suas classificações no $\mathrm{QCH} 2$, enquanto os outros três tinham classificações que caíram abaixo da faixa alta. Também é claro que em torno de um terço dos alunos ficaram amarrados em algum grau a tipos de crenças objetivistas ou subjetivistas (embora não simultaneamente, exceto Hannah e Katie), apesar de, talvez, 
menos ingênuas do que quando entraram no curso. A dificuldade da professora Danielle com o "problema do viés" atingiu sem dúvida também esses alunos. Para eles, parecia que a história permanecia interpretativa subjetivamente, e talvez perversamente, de um modo que fazia que eles desejassem mais objetividade para resolver a dificuldade. Contudo, o curso parecia ter pouca capacidade de ajudá-los a desenvolver ferramentas que pudessem assegurá-la. Como Danielle, eles permaneceram na maioria ou dualistas epistêmicos ou hesitantes numa fase transicional.

Ao tentar entender o passado, a influência da perspectiva é, sem dúvida, ubíqua e inescapável. Aprender ferramentas para construir critérios para lidar com a sua influência pode ser uma tarefa difícil. Até investigadores profissionais da história, que podem ser tidos como pensadores experientes e pessoas que manuseiam ferramentas e critérios, lutam com o que fazer em relação a isso e discutem entre si sobre a relação apropriada entre o conhecedor e o que ele pode saber sobre o passado (por exemplo, DAVIDSON \& LYTLE, 1992; DAVIS, 1988; FINLAY, 1988; MEGILL, 2007; NOVICK, 1988).

Uma terceira abordagem para representar esses dados é ir a cada caso através das classificações do QCH representadas no Quadro 1 num esforço para identificar quantos alunos demonstraram um claro padrão de crescimento em classificações criterialistas ao mesmo tempo que aumentaram suas classificações negativas em itens objetivistas e subjetivistas. A classificação de consistência é uma garantia desse padrão.

Nenhum aluno demonstrou $100 \%$ de consistência. Contudo, vários alunos chegaram perto, como por exemplo Lolly. Somente a sua classificação subjetivista na subescala de História se move na direção contrária das esperadas pelas experiências do curso, e também apenas muito levemente. Rizza é outro exemplo. Todas as suas classificações se movem na direção esperada, exceto que o seu objetivismo na subescala de EAH permanece o mesmo (embora se pretendesse uma classificação negativa forte) e suas classificações subjetivistas na mesma subescala são levemente atenuadas ao mesmo tempo que permanecem positivas. Alan é um terceiro caso semelhante. A única discrepância no padrão de história é que, na subescala $\mathrm{H}$, a sua classificação subjetivista se move de uma posição negativa para uma ambivalente. Ele parece estar dizendo aqui que ele não está certo sobre aquilo em que acredita. A história pode ser mais ou menos 
subjetiva, mas quanto e com que frequência ele não tem certeza e não está certo de que tem os critérios para saber a diferença. Ele pode também estar dizendo que se sente bem com esta ambivalência. Contudo, poderia criar impasses no seu pensamento à medida que ele luta com os resíduos do passado.

Bob é talvez o exemplo que está mais próximo de mostrar o movimento nas crenças nas direções pretendidas e com consistência. Ele começa com crenças criterialistas razoavelmente consistentes e então o seu padrão indica que a sua posição se fortalece um pouco. No entanto, como Rizza, ele tem várias classificações que permanecem sem mudança, sugerindo que o curso não teve muito impacto nele no que diz respeito às suas crenças. O padrão de Josie é virtualmente idêntico ao de Bob. Falaremos mais sobre o seu caso em breve. Pode ser que o curso tenha tido pouco valor de mudança epistêmica para aqueles que entraram nele com algumas posições epistêmicas um tanto consistentes e que se ligavam a como eles experienciaram o curso e entenderam os seus objetivos. Por exemplo, a metade dos alunos (n. = 9) que tinham as mais altas classificações iniciais de consistência (variando de 77 a 95\%) não tiveram nenhum aumento nessas classificações (ver Quadro 3).

A consistência de posição epistêmica - comum entre peritos da área (por exemplo,

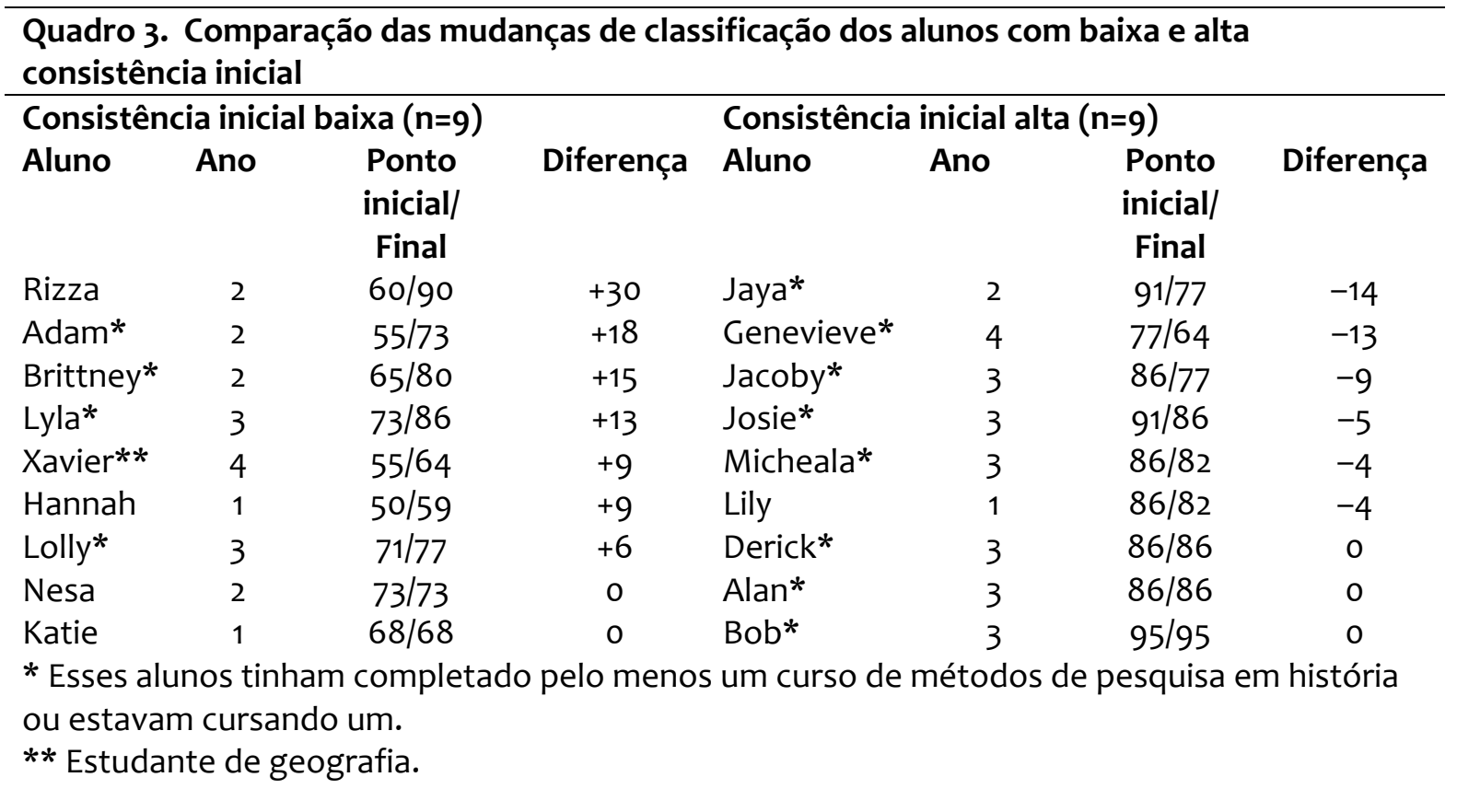


Totais:

0 = Consistência diminuída

$2=$ Sem mudança

7 = Consistência aumentada
Totais:

6 = Consistência diminuída

$3=$ Sem mudança

$0=$ Consistência aumentada

MAGGIONI et al., 2009) - permanece um traço altamente saliente nos esforços de identificar um movimento entre os alunos da entrada até a saída do curso. De modo geral, um padrão surpreendente de duas metades surgiu, isto é, aqueles nove alunos com a mais baixa consistência inicial viram os maiores aumentos em direção de posições mais estabilizadas, enquanto aqueles nove com a mais alta consistência inicial viram diminuir ou permanecer o mesmo (Quadro 3).

Argumentaríamos que o curso parecia ajudar os nove com classificações de consistência inicial mais baixa a esclarecer aspectos das suas crenças epistêmicas de modo que pudesse ajudá-los a estabilizar posições na direção do criterialismo sem necessariamente ajudá-los a tornar-se criterialistas maduros. Rizza (+30\%), Adam (+18), Brittney (+15\%) e Lyla (+13\%) são casos fortes neste ponto. Brittney, por exemplo, notou por escrito no fim de suas respostas às mudanças do QCH1 ao QCH2 que o curso teve um profundo efeito na sua reconsideração e clarificação das bases das suas crenças epistêmicas tanto sobre a história quanto sobre o ensino e a aprendizagem de história. Hannah, por outro lado, continuou a sofrer de uma considerável confusão e instabilidade epistêmica, apesar de ver sua consistência melhorar 9 pontos percentuais. A consistência de Hannah foi a menor dos 18 alunos, tanto no começo quanto no fim do curso (50/59). Seus comentários escritos no fim do Q $\mathrm{CH}_{2}$ refletiram esta confusão, mas ela disse que o curso a ajudou a ter mais clareza sobre algumas questões relacionadas à sua excessiva confiança inicia na crença de que a história fosse o que realmente aconteceu. Dois fatores que contribuíram podem ter sido o fato de que ela estava no primeiro ano e que a sua opção era licenciatura, e portanto não tinha sido exposta à história como um campo disciplinar, ou seja, relativo a alunos de história do terceiro ano, como Bob e Josie.

Para os nove mais consistentes no início, o curso não teve impacto criterialista ou aparentemente conseguiu desestabilizar as crenças. Muitos desses nove entraram no curso em transição e saíram em transição. É possível que o curso possa ter gerado 
consciência sobre as suposições epistêmicas simplesmente aceitas ou sem exame que causaram reexame e reduziram assim a consistência. Bob, cuja consistência continuou em 95\%, é uma exceção; ele estava razoavelmente confiante nas suas crenças criterialistas quando entrou no curso, e saiu com essa confiança intacta. Jaya foi o exemplo mais notável da tendência entre aqueles cuja consistência diminuiu. Ao analisar a sua queda de 91\% para $77 \%(-14)$, teorizamos que, com base na sua participação oral e respostas às atividades ocasionais do curso, ela entrou no curso razoavelmente astuta em selecionar respostas aos itens do QCH socialmente desejáveis - mas ainda não autoanalisadas, o que explica a sua alta consistência inicial. Contudo, o curso a provocou a questionar suas crenças de modo que, ao observar o $\mathrm{QCH}$, ela se tornou mais sensível àquelas crenças. Isto, por sua vez, fez que ela respondesse mais cautelosamente aos itens e posicionou as suas respostas mais perto das crenças transicionais (TR2) que ela de fato tinha. Poderia haver outros modos de interpretar o caso de Jaya, mas o que sugerimos aqui pareceu o mais plausível para nós.

Os outros traços deste modo de apresentar os dados são também notáveis. Desses nove com baixas classificações de consistência inicial, seis estavam nos primeiros anos da graduação. Da metade alta, somente dois estavam. E, em segundo lugar, na metade baixa, somente quatro alunos tinhas frequentado ou estavam frequentando o curso de métodos de pesquisa em história. Todos os alunos da metade alta, com exceção de um, tinham frequentado ou estavam frequentando tal curso. Isto pode sugerir que uma combinação de mais anos de experiência acadêmica (por exemplo, crescimento em maturidade intelectual) e questões epistemológicas provavelmente levantadas em um curso de métodos de pesquisa em história podem ajudar a reduzir grande parte da hesitação epistêmica que caracteriza os alunos iniciantes e aqueles que ainda não tinham feito o curso de métodos de pesquisa.

Mudanças de subescala em História $(H)$ e Ensino e Aprendizagem de História $(\mathrm{EAH})$

Poderia ser o caso de que a consistência da posição epistêmica de um aluno sobre a história não precise ser coerente com a sua posição sobre o ensino e a aprendizagem da 
matéria (50\% dos alunos tinham classificações de consistência criterialistas $\mathrm{H}$ mais altas do que classificações EAH criterialistas no começo). Isto poderia ser uma função do fato de eles aprenderem gradualmente mais sobre o que é história nos cursos de história (especialmente para aqueles que tinham feito cursos de pesquisa em história) e como estudantes de história sem que isso necessariamente influenciasse as suas visões sobre o ensino e aprendizagem que formadas principalmente nos aprendizados de observação nas aulas de Ensino Médio. Todos os 18 alunos ainda tinham que frequentar um curso formal que poderia ter começado a desafiar as ideias que eles tinham sobre o que significava ensinar história.

De modo geral, o padrão de mudança em classificações criterialistas, tanto na subescala $\mathrm{H}$ quanto na EAH, aumentou do QCH1 para o 2. Especificamente, dos 18, as classificações criterialistas por peso de 10 alunos (56\%) subiram nos itens $\mathrm{H}$, e 15 (78\%) nos itens EAH. Três classificações permaneceram sem mudança nos itens $\mathrm{H}$ e três nos itens EAH. Cinco classificações (28\%) caíram no primeiro e apenas um (6\%) no último. Jaya foi a única aluna que teve classificações criterialistas por peso diminuídas em cada categoria do QCH1 ao QCH2. Como observamos, quando ela viu o QCH, ela provavelmente tinha se tornado mais autoconsciente das suas crenças de modo que a levou a estudar os itens mais cuidadosamente e ajustar as respostas para atingir algum alinhamento. Por exemplo, a sua concordância no item 21 (a história como uma reconstrução razoável de acontecimentos passados baseada em evidência disponível) caiu em um ponto (5 para 4) e ela explicou isto observando que ficou confusa com o termo "razoável". Ela escreveu “...nem toda a história é necessariamente razoável ou faz sentido.” Esta poderia ter sido uma resposta à ênfase do curso na ideia de que se poderia distinguir entre relatos históricos que eram efetivamente nada mais do que opiniões infundadas e relatos que eram apoiados fortemente por evidência e portanto mais sólidos e aceitáveis enquanto alegações.

Os comprometimentos com o objetivismo na subescala de História caíram em 14 alunos (78\%) e subiram em 3 (17\%), enquanto uma (Michaela) não registrou mudança. As classificações da subescala de EAH caíram em 14 alunos (78\%), e a classificação de um (Xavier) subiu, e quatro (22\%) permaneceram sem mudança de um ao outro. De modo 
geral, houve menos movimento na direção não-intencional na subescala EAH, uma provável consequência do foco do curso no ensino e aprendizagem de história e especificamente em problemas e impasses associados com a ênfase excessiva na natureza objetivista da história (por exemplo, que a resposta certa é sempre alcançável) ao ensinar um assunto. Os comprometimentos epistêmicos com itens subjetivistas na subescala H caíram em quatro alunos (28\%), mas subiram em 11 (61\%). Dois alunos permaneceram sem mudanças nas suas respostas. Na subescala EAH, a concordância de itens subjetivistas caiu em seis alunos (33\%) e aumentou em 11 (61\%), ao passo que a classificação de apenas uma aluna (Michaela) permaneceu sem mudança. Assim como com Josie, falaremos mais sobre o seu caso em breve.

\section{Exemplos breves de quatro casos}

Genevieve. No fim do curso, categorizamos Genevieve, uma aluna do quarto ano do curso de museologia e história na segunda transição (TR2), embora ela permanecesse em concordância com o subjetivismo tanto na subescala $\mathrm{H}$ quanto na $\mathrm{EAH}$, e seus níveis de concordância realmente subissem do $\mathrm{QCH}_{1}$ ao $\mathrm{QCH} 2$, ao passo que as suas classificações de concordância na subescala H caíram. Ela também teve classificaçõos de consistência moderadamente fracas que caíram no QCH2. Perguntamo-nos se ela poderia ser melhor categorizada no primeiro estado transicional. Contudo, seus comentários e os dados de entrevista mostraram alguma integração das posições do objeto e do sujeito e as crenças sobre a história como sendo um empreendimento interpretativo que envolve pesadamente o investigador nas interações com os relatos.

Com relação ao item 11 do QCH, por exemplo, ela observou que ficou confusa com a afirmação: "a história é uma investigação crítica do passado", inicialmente, mas depois do $\mathrm{QCH} 2$, ela disse: “...Eu tenho uma ideia melhor de como a história trabalha e como o pensamento crítico pode vir de um número de diferentes perspectivas, o que de fato faz da história uma investigação crítica do passado. Trata-se de fazer perguntas." Com relação a construir relatos razoáveis baseados em evidência (QCH n. 18), ela observou: “É possível que um relato mais preciso pode ser construído na presença de evidências 
Finalmente, com relação aos fatos que falam por si (n. 16), ela argumentou que “Os fatos não falam por si porque há muitos 'fatos' em toda história. Você precisa interpretar os fatos" (grifo seu). Todas as observações implicam ou afirmam diretamente a presença do conhecedor (investigador) interagindo com o que se pretende saber (residua), sugerindo esforço epistêmico continuado para resolver com sucesso e harmonizar aquela relação, em vez de resignação ou lamento em face dela. Que ela tenha pendido para uma concordância crescente com a posição subjetivista não é necessariamente surpreendente, dada a sua hesitação epistêmica. Os dados da sua entrevista mostraram que ela ainda estava tentando resolver a questão do verdadeiro papel, das ferramentas e dos critérios que os investigadores têm e nos quais se apoiam quando interpretam os resíduos do passado. Colocar o subjetivismo entre parênteses ao fazer isso não foi algo que ela tinha conseguido fazer inteiramente.

Lily. Um caloura do curso de educação e afrodescendente de segunda geração, Lily estava também em transição epistêmica (TR2), embora suas classificações criterialistas por peso tenham mostrado em geral menos do que uma concordância direta. Suas classificações de consistência foram razoavelmente fortes, mas ficaram abaixo da faixa alta que tínhamos estabelecidos para a descrição como criterialista. Como Genevieve, Lily parecia estar se esforçando para harmonizar a relação entre o conhecedor e o que pode ser conhecido sobre o passado. Com relação a interpretações do passado que estão relacionadas à falta de evidência (item 5), Lily registrou uma forte discordância no QCH2. Ela observou que "A evidência está nos olhos do observador. Você poderia pensar que algo é evidência e outra pessoa poderia pensar que isso é inconsequente... isso é o que eu estava pensando." Inicialmente, Lily manteve uma forte concordância com a ideia de que a história é uma pesquisa crítica do passado. No QCH2, essa concordância foi atenuada. Para explicar essa mudança, ela disse que "Às vezes é alguém usando a história com as suas palavras para lavar o cérebro de alguém sobre um evento. Você sabe, até hoje, as pessoas dizem que [o Holocausto] não aconteceu." Esta questão tinha sido discutida pelo menos em duas ocasiões em aula. Suas explicações mostram que ela está lutando com o 
Lily sugeriu que tinha algumas ideias incipientes sobre os critérios e as ferramentas para lidar com um assunto epistêmico problemático. Ao responder sobre a sua mudança da concordância para a discordância com a afirmação de que "o passado é o que o historiador faz que ele seja", ela argumentou o seguinte:

Eu estava pensando que se você olha somente para... e lê o livro, você pode somente entender o que o historiador quer que você entenda. Mas esses livros de história tiram sua informação de algum lugar... se você permitir apenas que a sua opinião seja baseada na opinião de outra pessoa sem pesquisar por si mesmo - você sabe, você poderia ler um livro sobre um período histórico e se você ler apenas um livro, é a opinião que você vai ter. Mas, então, se você for pesquisar e, digamos, essa pessoa disser isto e aquela outra pessoa disser aquilo, então você pode pensar o que eu penso, e você pode chegar a uma síntese, ou você pode dizer que você não concorda com nenhuma delas.

Aqui ela observa os esforços para harmonizar o papel do conhecedor com o que pode ser conhecido dos objetos do passado e mostra a necessidade de um processo de pesquisa para ajudar essa harmonização, sugerindo a ideia da preponderância da evidência na formação da ideia de Kloppenberg (1989) de uma síntese provisória. Contudo, ela lança pouca luz sobre como é o processo ou como poderia ajudá-la a resolver as disputas. O sentido limitado de uma posição totalmente produtiva para avaliar e julgar as alegações de conhecimento era comum entre esses alunos, especialmente aqueles que ainda não tinham feito um curso de métodos de pesquisa em história.

Josie. Ela era uma aluna descendente de europeus do quarto ano do curso de história que teve educação doméstica, frequentou uma faculdade comunitária local por dois anos e depois foi transferida para a universidade. Sua educação doméstica foi caracterizado por um programa baseado em literatura, integrando a maior parte das disciplinas que ela aprendeu com seleções de literatura. Foi difícil descrever a influência do currículo de ensino doméstico nas suas ideias e nas suas crenças epistêmicas. Contudo, ela foi notavelmente coerente na sua posição epistêmica (depois apenas de Bob), como classificações por peso virtualmente mais altas em itens criterialistas no 
segundo QCH. Ela também externou o padrão criterialista ao mostrar uma discordância coerente com itens objetivistas e subjetivistas. Pensamos nela como talvez a única criterialista moderada entre os 18 alunos. Josie notou que ela se tinha beneficiado do curso de pesquisa em história que fizera no seu segundo ano, observando que ela "vê o método disciplinado de pesquisa necessário para escrever a história" (grifo seu).

Um elemento que foi acrescentado à segunda versão do curso que os alunos fizeram envolveu um esforço mais concentrado em ensinar explicitamente critérios específicos e procedimentos e uma heurística de análise histórica especialmente estratégicos para lidar com a evidência (por exemplo, as ideias da preponderância e da contextualização) e para tornar defensáveis alegações baseadas nela. Esses acréscimos se apoiaram em aprender a identificar o autor de um relato, a dar conta do seu contexto histórico, avaliar a perspectiva e as entrelinhas que poderiam conter e julgar sua confiabilidade em relação a outros relatos do período às questões que o investigador estava fazendo (cf. VANSLEDRIGHT, 2011). Essas estratégias ecoaram particularmente em Josie, que pôde integrá-las com o que ela tinha aprendido no curso de métodos de pesquisa em história. Ela observou que "aprender como identificar a perspectiva [...] é essencial para aprender como ver/fazer a história." Ela também acrescentou que "Nós podemos usar relatos [de primeira mão] para interpretar um relato geral como comentamos inúmeras vezes." Aqui ela sugere que o critério avaliativo de julgar uma história sob a luz de como ela usa relatos de primeira mão para defender suas alegações de conhecimento, uma prática muito comum na disciplina. Tal posicionamento nos sugere que, dos 18, Josie estava epistemicamente mais longe do contínuo de desenvolvimento em direção de uma posição criterialista do que seus colegas, com a possível exceção de Bob.

Michaela. Estudante do terceiro ano de história, descendente de europeus, que frequentou escolas públicas locais e tinha passado por um currículo de história tradicional, Michaela mostrou uma imobilidade nas classificações do seu QCH da primeira à segunda aplicação. Na subescala de EAH, com efeito, não houve mudança. Ela foi a única aluna com quem isso aconteceu. As classificações do seu QCH mostraram uma concordância de fraca a moderada com o criterialismo e discordâncias com o objetivismo 
e o subjetivismo. Interpretamos que ela estava no segundo nível de transição porque seus comentários sugeriam que ela, como muitos colegas seus, ainda estava tentando trabalhar crenças que iriam harmonizar com êxito a relação conhecedor/conhecido. Contudo, de muitas maneiras, ela também pareceu uma aluna universitária brilhante, mas muito tradicional, desejosa de ter boas notas e atingir um IA alto, ao mesmo tempo que estava se divertindo consideravelmente, e se formando e se qualificando para um trabalho bem pago. Muitas disciplinas universitárias eram algo para aguentar ao longo do percurso. Talvez como resultado, seus comentários em relação às poucas mudanças nos itens do QCH não revelaram nada e a entrevista lançou apenas um pouco de luz.

Ela estava consciente de que o conhecedor se depara com um desafio de entender o passado, que os impasses são frequentemente difíceis de superar e que o conhecedor precisa de vigilância extra e um julgamento fino na realização de sínteses. Contudo, não ficou claro se ela tinha estabelecido para si mesma um conjunto de critérios e processos estratégicos e analíticos para superar os impasses cognitivos. Ela pôde articulá-los bem mas frequentemente em termos gerais e sem maior especificação:

É preciso que você seja capaz de ler, e relativamente rápido. Você precisa saber como entender o viés, entender o que mais está acontecendo no mundo. [Você] precisa entender questões sobre quem, o quê, quando, por que e onde. [Você] precisa entender por que alguém está dizendo algo e como ele [chegou] à questão. ... O conhecimento de olhar dentro das coisas mais profundamente - habilidades de pensamento crítico.

Ela se mostrou diferente de Josie neste respeito, e o contraste entre essas duas alunas inteligentes serviu como um caso interessante de comparação das diferenças entre uma posição criterialista moderada e alguém em transição.

\section{Conclusão}

Para esses alunos universitários, a hesitação epistêmica pareceu ser comum. Trabalhar uma harmonização exitosa entre eles como conhecedores e o que pode ser conhecido sobre o passado através dos seus objetos remanescentes é uma tarefa difícil. Mas nós argumentaríamos que ela é necessária: Ser capaz de pensar historicamente e de fazer a história depende do desenvolvimento de algo que se parece com o que estamos 
descrevendo como criterialismo (ou o que Kloppenberg chama de hermenêutica pragmática). Um apoio excessivo na confiança em objetos do passado para produzir as suas histórias num modo não-mediado e não-problematizado não é possível. Nem tampouco um apoio excessivo na subjetividade do conhecedor para resolver a questão de como dar mais profundamente sentido ao passado.

Se aceitamos a premissa de que para trabalhar uma posição harmonizada exitosa requer, em parte, experiências que forneçam oportunidades para praticar a ação de fazer a história e assumir aspectos difíceis do pensamento histórico, então mais experiências como essas é melhor do que menos. Durante essas experiências, também pareceria fazer sentido aos aprendizes desenvolver um vocabulário para descrever os seus esforços. Isto permitiria a eles estar mais conscientes de como seus posicionamentos epistêmicos mudam e os capacitaria a ter mais controle sobre um avanço produtivo. As experiências nos departamentos de história (cursos de métodos de pesquisa) e em programas de preparação de professores estão implicadas pelos resultados deste estudo.

É importante notar as limitações deste trabalho. Este foi um estudo investigativo feito com recursos de coleção de dados limitados. Não fomos capazes de produzir registros de relatórios verbais sobre como os alunos responderam às duas aplicações do QCH. Portanto, confiamos nos relatórios feitos pelos próprios participantes sobre a natureza das suas mudanças epistêmicas de uma à outra aplicação, e esses relatórios podem ser de algum modo não-confiáveis, uma vez que os participantes frequentemente tinham dificuldade em articular as mudanças em concepções epistêmicas simplesmente aceitas. Como resultado, a intensidade da hesitação e da mudança, sob quais circunstâncias e em relação a quais experiências específicas do curso, tudo isso é baseado em nossas estimativas inferenciais.

Embora acreditemos que os dados obtidos com o QCH são válidos e reveladores, o que eles nos dizem é menos do que preciso. Esforços mais extensivos de coleta de dados seriam provavelmente necessários para contrabalançar a confiança na realização de interpretações altamente inferenciais. Como observamos, relatórios verbais poderiam ser necessários. Entrevistas mais extensas com mais participantes poderiam também ajudar. Estas poderiam ser usadas mais eficazmente para identificar as experiências do curso que 
ajudaram a promover mudanças epistêmicas e a reduzir aquelas que produziram menos impactos. Contudo, fazer estudos investigativos pode esclarecer que trabalho ainda precisa ser feito.

\section{Referências}

BENDIXEN, Lisa. A process model of epistemic belief change. In: HOFER, Barbara. K. and PINTRICH, Paul R. (Eds.). Personal epistemology: The Psychology of beliefs about knowledge and knowing. Mahwah, NJ: Earlbaum, 2002, p. 191-209.

BRITZMAN, Deborah. Practice makes practice. A critical study of learning to teach. New York, NY: SUNY Press, 1991.

BUEHL, Michelle M., \& ALEXANDER, Patricia A. Beliefs about academic knowledge. Educational Psychological Review. v. 13, p. 385-418, 2001.

CUBAN, Larry. History of teaching in social studies. In: Shaver, James P. (Ed.). Handbook of research on social studies teaching and learning. New York, NY: Macmilian, 1991, p. 197-209.

DAVIDSON, James. \& LYTLE, Mark Hamilton. After the fact: The art of historical detection. New York, NY: McGraw Hill, 1992.

DAVIS, Natalie Zemon. On the lame. American Historical Review. v. 93, p. 572-603, 1988.

FINLAY, Robert. The refashioning of Martin Guerre. American Historical Review. v. 93, p. 553-571, 1988.

HOFER, Barbara. Personal epistemology research: Implications for learning and teaching. Journal of Educational Psychology Review. v. 13, n.4, p. 353-383, 2001.

HOFER, Barbara. (2002). Personal epistemology as a psychological and educational construct: An introduction. In: HOFER, Barbara. \& PINTRICH, Paul (Eds.). Personal epistemology: The psychology of beliefs about knowledge and knowing. Mahwah, NJ: Erlbaum, 2002, p. 3-15.

HOFER, Barbara; PINTRICH, Paul. The development of epistemological theories: Beliefs about knowledge and knowing and their relation to learning. Review of Educational Research. v. 67. n.1, p. 88-140, 1997. 
HICKS, David, DOOLITTLE, Peter, \& LEE, John. Social studies teachers' use of classroombased and web-based historical primary sources. Theory and Research in Social Education. v. 32, n. 2, p. 213-247, 2004.

KENNEDY, Mary (2005). Inside teaching: How classroom life undermines reform. Cambridge: Harvard University Press, 2005.

KING, Patricia, \& KITCHENER, Karen Strohm. The reflective judgment model: Twenty years of research on epistemic cognition. In: HOFER, Barbara \& PINTRICH, Paul R. (Eds.). Personal epistemology: The psychology of beliefs about knowledge and knowing. Mahwah, NJ: Erlbaum, 2002, p. 37-61.

KLOPPENBERG, James. Objectivity and historicism: A century of American historical writing. American Historical Review. v. 94, p. 1011-1030, 1989.

KUHN, Deanna, \& WEINSTOCK, Michael (2002). What is epistemological thinking and why does it matter? In: HOFER, Barbara K. \& PINTRICH, Paul R. (Eds.). Personal epistemology: The psychology of beliefs about knowledge and knowing. Mahwah, NJ: Erlbaum, 2002, p. 121-145.

LAMPERT, Magdalene (1990). When the problem is not the question and the solution is not the answer: Mathematical knowing and teaching. American Educational Research Journal. v. 27, p. 29-63, 1990.

LEE, Peter. Understanding History. In: SEIXAS, Peter (Ed.). Theorizing historical consciousness. Toronto: University of Toronto Press, 2004, p. 129-164.

LEE, Peter, \& ASHBY, Rosalyn (2000). Progression in historical understanding among students ages 7-14. In: STERNS, Peter; SEIXAS, Peter \& WINEBURG, Samuel (Eds.). Knowing, teaching, and learning history: National and international perspectives. New York: NYU Press, 2000, p. 192-222.

LEE, Peter, \& SHEMILT, Denis. A scaffold, not a cage: Progression and progression models in history. Teaching History. v. 113, p. 13-24, 2003.

LORTIE, Dan. Schoolteacher. Chicago, IL: University of Chicago Press, 1975.

MAGGIONI, L., ALEXANDER, P., \& VANSLEDRIGHT, B. At a crossroads? The development of epistemological beliefs and historical thinking. European Journal of School Psychology. v. 2, n. 1-2, p. 169-197, 2004. 
MAGGIONI, Liliana, VANSLEDRIGHT, Bruce, \& ALEXANDER, Patricia. Walking on the borders: A measure of epistemic cognition in history. The Journal of Experimental Education. v. 77, n. 3, p. 187-213, p. 2009.

MAGGIONI, Liliana; VANSLEDRIGHT, Bruce; \& REDDY, Kim. Epistemic talk in history. In: biennial conference of the European Association for Research on Learning and Instruction (EARLI). Amsterdam, Netherlands, 2009.

MCDIARMID, Williamson; \& VINTEN-JOHANSON, Peter (2000). A catwalk across the great divide: Redesigning the history teaching methods course. In STERNS, Peter; SEIXAS, Peter, \& WINEBURG, Samuel (Eds.). Knowing, teaching, and learning history: National and international perspectives. New York: New York University Press, 2000, p. 156-177.

MEGILL, Allan. Historical knowledge, historical error: A contemporary guide to practice. Chicago: University of Chicago Press, 2007.

MUIS, Krista R.; BENDIXEN, Lisa D.; \& HAERLE, Florian. Domain-generality and domainspecificity in personal epistemology research: Philosophical and empirical reflections in the development of a theoretical framework. Educational Psychology Review. v. 18, p. 354, 2006.

NOVICK, Peter. That noble dream: The objectivity question and the American historical profession. Cambridge, UK: Cambridge University Press, 1988.

PAXTON, Robert J. A deafening silence: History textbooks and students who read them. Review of Educational Research. v. 69, p. 315-339, 1999.

SCHOENFIELD, Allan. Beyond the purely cognitive: Belief systems, social cognitions, and metacognitions as driving forces in intellectual performance. Cognitive Science. v. 7, p. $329-363,1983$.

SCOTT, Joan W. After history? Common Knowledge. v. 5, p. 9-26, 1996.

STRØMS $\varnothing$, Helge I., \& BRÅTEN, Ivair (2002). Norwegian law students' use of multiple sources while reading expository texts. Reading Research Quarterly. v.37, p. 208-227, 2002.

VANSLEDRIGHT, Bruce. What does it mean to think historically and how do you teach it? In: PARKER, Walter (Ed.). Social studies today: Research and practice. New York, NY: Routledge, 2010, p. 113-120.

VANSLEDRIGHT, Bruce (2011). The challenge of rethinking history education: On practices, theory, and policy. New York, NY: Routledge, 2011. 
VANSLEDRIGHT, Bruce \& FRANKES, Lisa. Concept and strategic knowledge development in historical study: A comparative exploration in two fourth grade classrooms. Cognition and Instruction. v. 18, n. 2, p. 239-283, 2000.

WINEBURG, Samuel. Historical thinking and other unnatural acts: Charting the future of teaching the past. Philadelphia, PA: Temple University Press, 2001.

\section{Apêndice}

Lista de Declarações do Questionário de Crenças sobre a História

1. É fundamental que os alunos sejam ensinados a apoiar o seu raciocínio em evidência;

2. A história é simplesmente uma questão de interpretação.

3. Um relato histórico é o produto de um método disciplinado de investigação.

4. Os alunos que leem muitos livros de história aprendem que o passado é o que o historiador faz que ele seja.

5. A discordância sobre o mesmo evento no passado é algo que se deve à falta de evidência.

6. Bons alunos sabem que a história é basicamente uma questão de opinião.

7. Os alunos precisam aprender a lidar com evidências conflitantes.

8. As alegações históricas não podem ser justificadas, uma vez que elas são simplesmente uma questão de interpretação.

9. Boas habilidades de leitura e compreensão geral são suficientes para aprender bem a história.

10. Uma vez que não há modo de saber o que realmente aconteceu no passado, os alunos podem acreditar na história que eles quiserem.

11. A história é uma investigação crítica sobre o passado.

12. O passado é o que o historiador faz que ele seja.

13. Comparar fontes e entender a perspectiva do autor são componentes essenciais do processo de aprendizado da história. 
14. É impossível saber algo com certeza sobre o passado, uma vez que nenhum de nós estava lá.

15. O conhecimento do método histórico é fundamental tanto para os historiadores quanto para os alunos.

16. Os fatos falam por si.

17. Os alunos precisam estar conscientes de que a história é essencialmente uma questão de interpretação.

18. Relatos razoáveis podem ser construídos mesmo na presença de evidências conflitantes.

19. Nem mesmo testemunhas oculares concordam umas com as outras, e portanto não há modo de saber o que aconteceu.

20. Os professores não deveriam questionar as opiniões dos alunos sobre a história, apenas verificar que eles conhecem os fatos.

21. A história é uma reconstrução razoável das ocorrências do passado baseada em evidência disponível.

22. Não há evidência em história. 
Crenças epistêmicas em mudança? Um estudo investigativo do conhecimento entre futuros professores de

Recebido em: 01/01/2013 Aprovado em: 10/03/2014

Universidade do Estado de Santa Catarina - UDESC

Programa de Pós-Graduação em História - PPGH

Revista Tempo e Argumento Volume 06 - Número 11 - Ano 2014 tempoeargumento@gmail.com 